\title{
10 \\ Fish Remains at Man Bac
}

\author{
Takeji Toizumi ${ }^{1}$, Nguyen Kim Thuy ${ }^{2}$, Junmei Sawada ${ }^{3}$ \\ ${ }^{1}$ Institute of Comparative Archaeology, Waseda University, Japan \\ 2 The Vietnamese Institute of Archaeology \\ ${ }^{3}$ School of Medicine, St. Marianna University, Japan
}

\begin{abstract}
Many fish remains were recovered from excavations at Man Bac during the 2005 and 2007 seasons. This chapter focuses on the identification of fish remains recovered in the 2004-5 season, with some general observations made on the 2007 assemblage. In addition, a discussion of the aquatic palaeoenvironment surrounding the site and the fishing activities of its inhabitants is outlined here. The analysis was carried out at the Institute of Archaeology, Hanoi in 2008. The elements considered for identification were maxillaries, premaxillaries, dentaries, angulars, quadrates, vertebrae and other identifiable elements. These specimens were identified through comparison with skeletal specimens of modern fishes.
\end{abstract}

\section{MATERIALS AND RESULTS}

\section{Identifications}

The identification results are shown in Table 10.1. A total of 722 specimens were available for analysis. Separating them by strata; specifically Layer I, II, and III, yielded 561, 121, and 40 specimens respectively, with most of the specimens coming from Layer I, and the number decreasing in the lower layers.

As with the mammalian assemblage (see Chapter 9) the Man Bac fish assemblage was collected by a combination of in situ recovery during excavation and the wet sieving of two excavation squares (squares E3 and G1).

Among the material analysed, 692 specimens were identified to the level of order or lower, and 4 taxa of Chondrichthyes (Elasmobranchii) plus 10 taxa of Osteichthyes (Teleostei) were identified. In addition, there were 25 unidentified Osteichthyes specimens (Figure 10.1, No. 13-17). Acanthopagrus sp. (black seabreams) were the most numerous (54\% of total MNI), followed by Lates calcarifer (barramundi), Siluriformes (catfishes), Rajiformes (rays), Lamnidae / Lamniformes (sharks), and Serranidae (groupers). This pattern is basically the same from Layer I to Layer III (Table 10.2, Figure 10.2).

\section{Brief Description of the Dominant Taxa}

Because a comparison with modern fish specimens was insufficiently detailed, the identification of the Elasmobranchii (Sharks and Rays) remains uncertain. Most of the shark vertebrae are from Carcharhinidae or similar types (Figure 10.1, No. 2), 


\section{T. TOIZUMI ET AL.}

Table 10.1 Fish remains from the 2004-2005 excavation season at Man Bac.

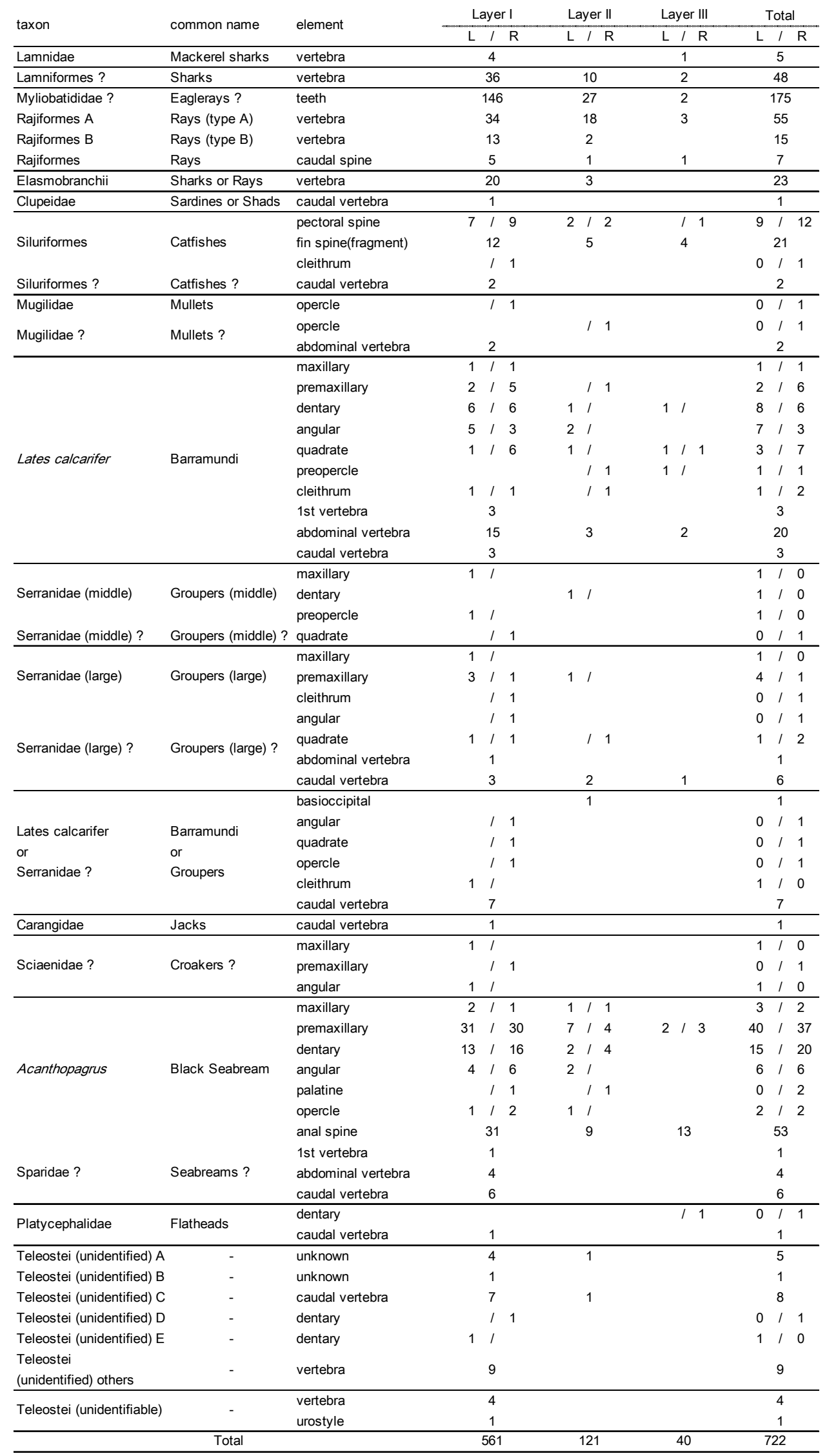


10. FISH REMAINS

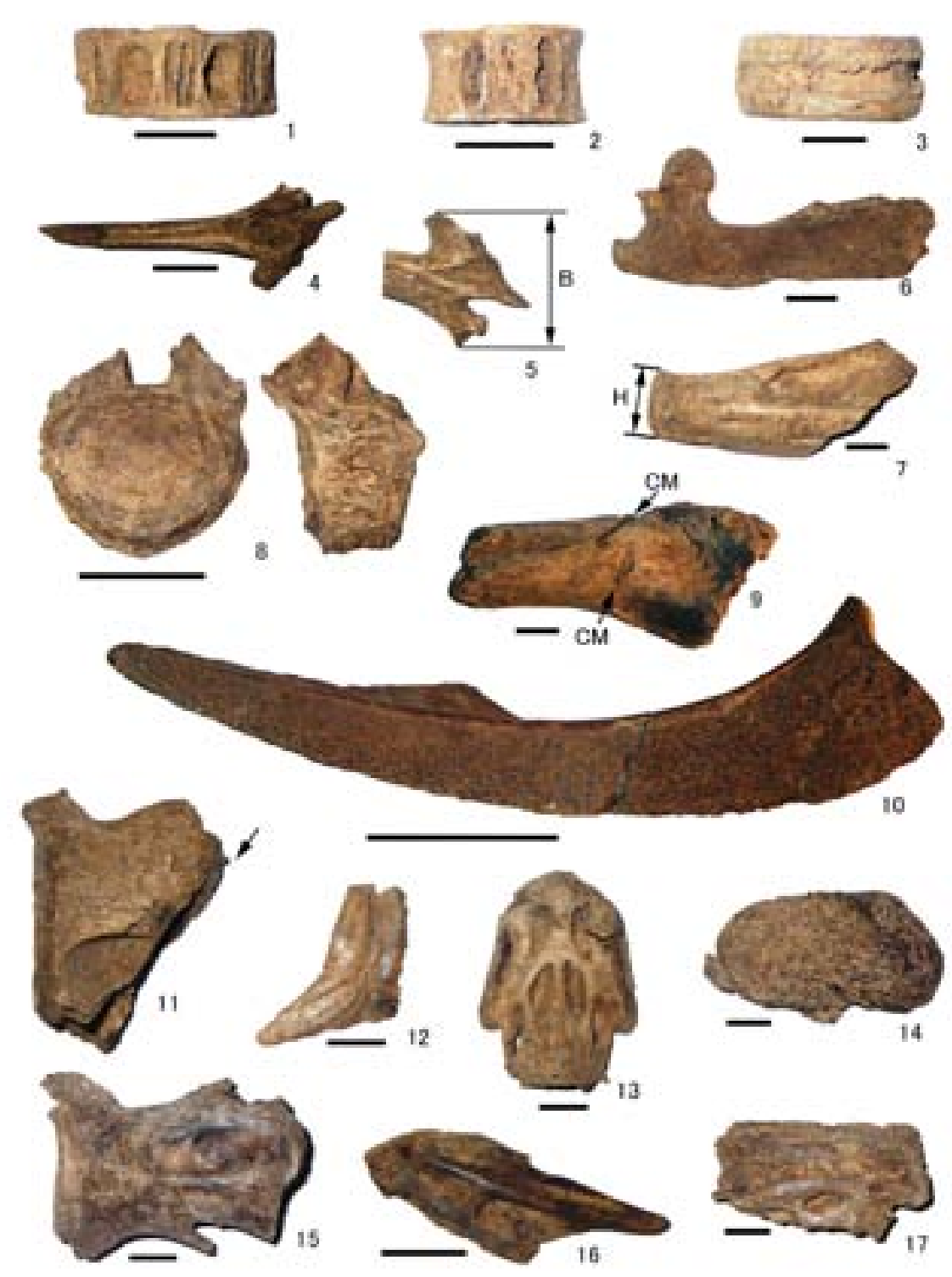

Figure 10.1 Fish remains from Man Bac.

1 Lamnidae vertebra, 2 Carcharhinidae? vertebra, 3 Rajiformes A vertebra, 4-5 Siluriformes pectoral spine (B: greatest breadth of the proximal end), 6-7 Lates calcarifer [6 premaxillary, 7 dentary (H: height of the anterior end)], 8 and 11 Serranidae (large) ? [8 abdominal vertebra, 11 caudal vertebra (artificially cut?)] , 9-10. Serranidae (large) [9 maxillary (CM: cut mark), 10 premaxillary], 12. Serranidae (middle) preopercle, 13 Teleostei (unidentified) A, 14 Teleostei (unidentified) B, 15 Teleostei (unidentified) C caudal vertebra, 16. Teleostei (unidentified) D dentary, 17 Teleostei (unidentified) E dentary. scale bar: 8 and 10: $5 \mathrm{~cm}$, others: $1 \mathrm{~cm}$ 

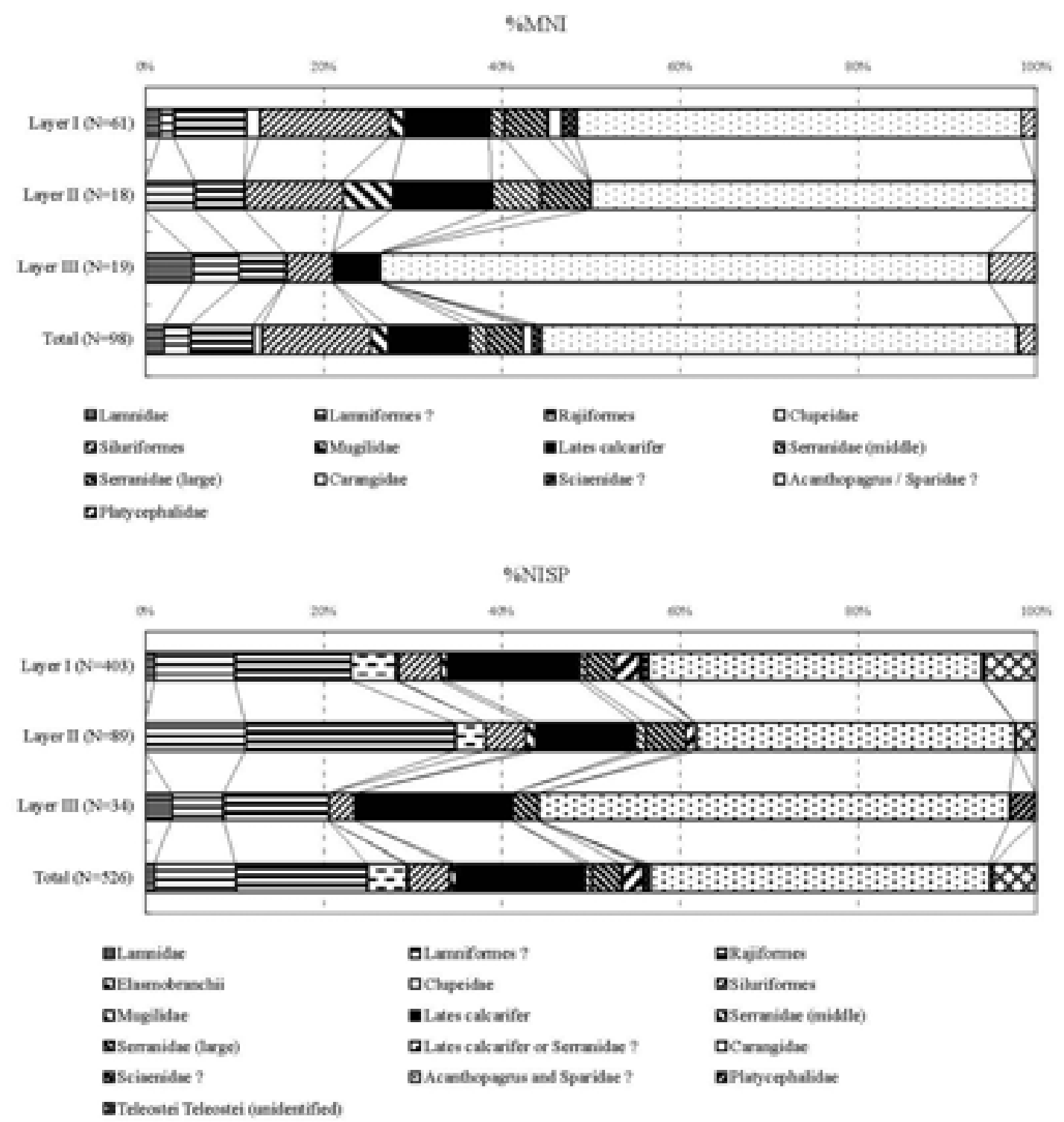

Figure 10.2 Assemblage of fish remains from Man Bac 2004-2005. upper: \%MNI, lower: \%NISP.

but there are also some from Lamnidae (Mackerel sharks, Figure 10.1, No.1). Most of these vertebrae are small to medium in size with diameters around $2 \mathrm{~cm}$.

The Rajiformes teeth are probably from Myliobatididae (Eaglerays) and there is a variety of sizes with the largest specimen having a width of $4 \mathrm{~cm}$. Among the Rajiformes vertebrae, there are those that exhibit a pulley-like shape (Rajiformes A, Figure 10.1, No.3), and those that don't (Rajiformes B). Most of the Rajiformes A vertebrae are small with diameters of 9 to $13 \mathrm{~mm}$, but there are also some medium to large ones with diameters of 18 to $36 \mathrm{~mm}$. The size of the Rajiformes B vertebrae is essentially the same as the A.

As for the Siluriformes, the Man Bac collection at hand and comparative research on modern specimens are insufficient, so difficult to identify to taxonomic family. The greatest breadth of the proximal end of the pectoral spine (Figure 10.1, No. 5) is 7 to $18 \mathrm{~mm}$, which at least identifies them as relatively large fishes. Lates calcarifer is also limited to relatively large fishes. The height of the anterior end of the dentary (Figure 10.1, No. 7) is 14.5 to $19.1 \mathrm{~mm}$. 
Table 10.2 Assemblage of fish remains from Man Bac 2004-2005.

\begin{tabular}{|c|c|c|c|c|c|c|c|c|c|}
\hline \multirow{2}{*}{ taxon } & \multirow{2}{*}{ common name } & \multicolumn{4}{|c|}{ NISP } & \multicolumn{4}{|c|}{$\mathrm{MNI}$} \\
\hline & & Layer I & Layer II & Layer III & Total & Layer I & Layer II & Layer III & Total \\
\hline Lamnidae & Mackerel sharks & 4 & 0 & 1 & 5 & 1 & 0 & 1 & 2 \\
\hline Lamniformes? & Sharks & 36 & 10 & 2 & 48 & 1 & 1 & 1 & 3 \\
\hline Rajiformes A & Rays (type A) & 34 & 18 & 3 & 55 & & & & \\
\hline Rajiformes B & Rays (type B) & 13 & 2 & 0 & 15 & 5 & 1 & 1 & 7 \\
\hline Rajiformes & Rays & 5 & 1 & 1 & 7 & & & & \\
\hline Elasmobranchii & Sharks or Rays & 20 & 3 & 0 & 23 & - & - & - & - \\
\hline Clupeidae & Sardines or Shads & 1 & 0 & 0 & 1 & 1 & 0 & 0 & 1 \\
\hline Siluriformes & Catfishes & 17 & 4 & 1 & 22 & 9 & 2 & 1 & 12 \\
\hline Siluriformes? & Catfishes? & 2 & 0 & 0 & 2 & & 2 & 1 & \\
\hline Mugilidae & Mullets & 1 & 0 & 0 & 1 & 1 & 1 & 0 & 2 \\
\hline Mugilidae? & Mullets? & 2 & 1 & 0 & 3 & & 1 & 0 & 2 \\
\hline Lates calcarifer & Barramundi & 59 & 10 & 6 & 75 & 6 & 2 & 1 & 9 \\
\hline Serranidae (middle) & Groupers (middle) & 2 & 1 & 0 & 3 & 1 & 1 & 0 & 2 \\
\hline Serranidae (middle)? & Groupers (middle)? & 1 & 0 & 0 & 1 & & & & \\
\hline Serranidae (large) & Groupers (large) & 6 & 1 & 0 & 7 & 3 & 1 & 0 & 4 \\
\hline Serranidae (large) ? & Groupers (large)? & 7 & 3 & 1 & 11 & & & & \\
\hline $\begin{array}{l}\text { Lates calcarifer } \\
\text { or Serranidae? }\end{array}$ & Barramundi or Groupers & 11 & 1 & 0 & 12 & - & - & - & - \\
\hline Carangidae & Jacks & 1 & 0 & 0 & 1 & 1 & 0 & 0 & 1 \\
\hline Sciaenidae? & Croakers? & 3 & 0 & 0 & 3 & 1 & 0 & 0 & 1 \\
\hline Acanthopagrus & Black Seabream & 138 & 32 & 18 & 188 & 31 & 9 & 13 & 53 \\
\hline Sparidae ? & Seabreams? & 11 & 0 & 0 & 11 & 31 & $y$ & 13 & 53 \\
\hline Platycephalidae & Flatheads & 1 & 0 & 1 & 2 & 1 & 0 & 1 & 2 \\
\hline Teleostei (unidentified) A & - & 4 & 1 & 0 & 5 & - & - & - & - \\
\hline Teleostei (unidentified) B & - & 1 & 0 & 0 & 1 & - & - & - & - \\
\hline Teleostei (unidentified) C & - & 7 & 1 & 0 & 8 & - & - & - & - \\
\hline Teleostei (unidentified) D & - & 1 & 0 & 0 & 1 & - & - & - & - \\
\hline Teleostei (unidentified) E & - & 1 & 0 & 0 & 1 & - & - & - & - \\
\hline $\begin{array}{l}\text { Teleostei } \\
\text { (unidentified) others }\end{array}$ & - & 9 & 0 & 0 & 9 & - & - & - & - \\
\hline Teleostei (unidentifiable) & - & 5 & 0 & 0 & 5 & - & - & - & - \\
\hline \multicolumn{2}{|c|}{ Total } & 403 & 89 & 34 & 526 & 62 & 18 & 19 & 99 \\
\hline
\end{tabular}

There are both medium and large specimens of Serranidae, with the large type being more numerous. Among the measurable specimens of the large type, the longest premaxillary is $197 \mathrm{~mm}$ (Figure 10.1, No.10). The greatest breadth of an abdominal vertebra is $71 \mathrm{~mm}$ (Figure 10.1, No. 8), which is the largest size for Osteichthyes. The medium type has an estimated body length of 30 to $50 \mathrm{~cm}$, which is significantly smaller than the large type (Figure 10.1, No.12). Most of the Acanthopagrus sp. are adult fish.

\section{Materials Recovered by Sieving}

The identification results for the materials from Square E3 (1mm sieve) in Layer I are presented in Table 10.3. Seven specimens each of Rajiformes and Acanthopagrus sp., and 1 specimen each of Clupeidae, Mugilidae and Sparidae were identified. In addition, there were 5 unidentified specimens of Teleostei, Clupeidae, Mugilidae and unidentified Teleostei, which were small-sized fishes, unlike those seen in the materials collected through in situ excavation.

\section{Materials Recovered from the 2007 Excavation}

Many fish remains were also recovered in the 2007 excavation. As with the 20045 season, fish remains were collected by a combination of in situ recovery during excavation and the intensive sieving $(1 \mathrm{~mm})$ of selected squares in Trench 2, layer 1. 


\section{T. TOIZUMI ET AL.}

In general, the same specimens of fish are seen in both seasons of excavation. The identification results of the sieved assemblage are shown in Table 10.4. Nine specimens of Rajiformes, 4 specimens each of Acanthopagrus sp. and Sparidae, plus 1 specimen each of Cyprinidae, Mugilidae, and Serranidae were identified. In addition, there were 4 unidentified specimens of Teleostei (possibly Cyprinidae or Siluformes). Cyprinidae, Mugilidae and the unidentified Teleostei are all small-sized fishes.

\begin{tabular}{|c|c|c|c|c|}
\hline taxon & common name & element & $\mathrm{L} / \mathrm{R}$ & $\mathrm{N}$ \\
\hline Rajiformes A & Rays type A & vertebra & & 1 \\
\hline Elasmobranchii & Sharks or Rays & vertebra & & 6 \\
\hline Clupeidae & Sardines or Shads & caudal vertebra & & 1 \\
\hline Mugilidae? & Mullets ? & abdominal vertebra & & 1 \\
\hline \multirow{4}{*}{ Acanthopagrus } & \multirow{4}{*}{ Black Seabream } & premaxillary & $\mathrm{L}$ & 4 \\
\hline & & premaxillary & $\mathrm{R}$ & 1 \\
\hline & & dentary & $\mathrm{R}$ & 1 \\
\hline & & angular & $\mathrm{R}$ & 1 \\
\hline Sparidae? & Seabreams? & caudal vertebra & & 1 \\
\hline Teleostei (unidentified) & - & vertebra & & 5 \\
\hline \multicolumn{2}{|c|}{ Total } & & & 22 \\
\hline
\end{tabular}

Table 10.4 Fish remains collected by sieving from area H2 in layer I (2007).

\begin{tabular}{|c|c|c|c|c|c|}
\hline taxon & common name & element & $\mathrm{L} / \mathrm{R}$ & $\mathrm{N}$ & remarks \\
\hline Myliobatididae? & Eaglerays ? & teeth & & 2 & \\
\hline Rajiformes A & Rays (type A) & vertebra & & 7 & \\
\hline Elasmobranchii & Sharks or Rays & vertebra & & 3 & \\
\hline Cyprinidae & minnows or carps & abdominal vertebra & & 1 & \\
\hline Mugilidae? & Mullets? & abdominal vertebra & & 1 & \\
\hline Serranidae? & Groupers? & caudal vertebra & & 1 & \\
\hline $\begin{array}{l}\text { Lates calcarifer or } \\
\text { Serranidae? }\end{array}$ & Barramundi or Groupers & angular & L & 1 & \\
\hline \multirow{4}{*}{ Acanthopagrus } & \multirow{4}{*}{ Black Seabream } & premaxillary & L & 1 & \\
\hline & & dentary & $\mathrm{R}$ & 1 & \\
\hline & & angular & $\mathrm{L}$ & 1 & \\
\hline & & opercle & $\mathrm{R}$ & 1 & \\
\hline \multirow{3}{*}{ Sparidae? } & \multirow{3}{*}{ Seabreams? } & abdominal vertebra & & 2 & \\
\hline & & caudal vertebra & & 2 & \\
\hline & & caudal vertebra & & 1 & Cyprinidae? \\
\hline \multirow{3}{*}{ Teleostei (unidentified) } & \multirow{3}{*}{ - } & quadrate & $\mathrm{R}$ & 1 & Siluriformes? \\
\hline & & abdominal vertebra & & 1 & Siluriformes? \\
\hline & & caudal vertebra & & 1 & Siluriformes? \\
\hline \multirow[t]{2}{*}{ Teleostei (unidentifiable) } & - & vertebra & & 2 & \\
\hline & Total & & & 30 & \\
\hline
\end{tabular}

\section{DISCUSSION}

\section{Palaeoenvironmental Reconstruction Based on Fish Remains}

The habitat types of the identified fishes are listed in Table 10.5. Most of the fishes identified are types that inhabit marine (littoral) or brackish waters (Figure 10.3) (Masuda et al., 1980; Masuda and Kobayashi, 1994). In particular, Acanthopagrus sp., which comprised more than half of the fish remains, mainly inhabits embayments and lagoons with relatively low salinity, or brackish waters such as estuaries and mangrove wetlands (Masuda et al., 1980; Masuda and Kobayashi, 1994). Lates calcarifer inhabit a variety of areas, from marine (littoral) 
waters to downstream areas of relatively large rivers. The specific habitats of the sharks and rays are uncertain due to insufficient identification, but it is certain that they are marine species. Because these fish remains were recovered in large numbers, there is no doubt that marine embayments or lagoons existed near the site.

There are both freshwater and marine species of Siluriformes (Masuda et al., 1980; Masuda and Kobayashi, 1994), but since the excavated remains have not been identified to the family level so far, their habitats are uncertain. As for aquatic animals besides fish, the remains of large Trionychidae (soft-shelled turtles) are common. Since Trionychidae live in freshwater, it can be assumed that there was a freshwater environment of a certain size near the site.

In summary, we can ascertain that there was a series of aquatic environments, from marine embayments or lagoons to freshwater ponds in the vicinity of the site (Figure 10.4). Compared to the current landscape surrounding Man Bac, and the aquatic environment along the northern Vietnam coast, the area was likely to have been similar to present day Ha Long Bay and the downstream basins of the rivers flowing into the bay. On the other hand, Serranidae inhabit rocky or coral reefs facing the open sea (Masuda et al., 1980; Masuda and Kobayashi, 1994), so there is a possibility that such an environment also existed in portions of the coastal area near the site.

\section{Characteristics of Fishing Activities Estimated From Fish Remains}

The dominant fishes caught at this site consist of Acanthopagrus sp., sharks and rays, Lates calcarifer, Siluriforme and Serranidae. Based on their habitats, as described above, it is likely that the main fishing grounds ranged from embayments or lagoons to brackish waters such as estuaries near the site (see Table 10.6). Lates calcarifer and Siluriformes were possibly caught in freshwater environments, but this is not certain. Combined with the low frequency of freshwater fish such as Cyprinidae, it is likely that freshwater fishing activities were of relatively limited importance.

Since Serranidae have a different habitat from other fishes, and most of their remains recovered were of an extremely large size, they may have been imported. Among the artefacts recovered from the site, those possibly used as fishing tools are bone pointed tools, bone harpoons and stone net sinkers. In particular, bone pointed tools were numerous (Dung 2006). Further research is required to clarify the relationship between these tools and the fishes identified, but it seems quite likely that the many bone pointed tools were used to catch Acanthopagrus sp. (Toizumi, 1988, 2000).

The tendency towards large individuals of Siluriforme, Lates calcarifer and Serranidae is a unique characteristic of the assemblage. Since most of the analysed materials were collected through in situ excavation, there is a possibility that bones from smaller fish are missing due to sampling issues, but even considering that, the tendency towards large fish is clear. It can be hypothesised that these fishes were caught using tools such as spears, or hooks and lines, with a strong selectivity for larger individuals. Serranidae, in particular, were probably caught by angling (hook 


\section{T. TOIZUMI ET AL.}

Table 10.5 Habitats of fishes identified at Man Bac.

\begin{tabular}{llcll}
\multirow{2}{*}{ taxon } & common name & total \%MNI & \multicolumn{2}{c}{ habitat } \\
\cline { 5 - 5 } \cline { 4 - 5 } in Man Bac 2005 & \multicolumn{1}{c}{ marine / freshwater } & remarks \\
\hline Lamnidae & Mackerel sharks & 2.0 & marine (open sea - littoral) & \\
Lamniformes ? & Sharks & 3.0 & marine (open sea - littoral) & \\
Rajiformes & Rays & 7.1 & marine (open sea - littoral) & \\
Clupeidae & Sardines or Shads & 1.0 & marine (open sea - littoral) - brackish \\
Cyprinidae & minnows or carps & - & freshwater - brackish & \\
Siluriformes & Catfishes & 12.1 & marine (littoral) - freshwater & \\
Mugilidae & Mullets & 2.0 & marine (littoral) - brackish & \\
Lates calcarifer & Barramundi & 9.1 & marine (littoral) - freshwater & \\
Serranidae & Groupers & 6.1 & marine (littoral) & rocky bottom \\
Carangidae & Jacks & 1.0 & marine (open sea - littoral) & \\
Sciaenidae ? & Croakers ? & 1.0 & marine (littoral) ? & \\
Acanthopagrus & Black Seabream & 53.5 & marine (littoral) - brackish & sandy bottom \\
Platycephalidae & Flatheads & 2.0 & marine (littoral) &
\end{tabular}

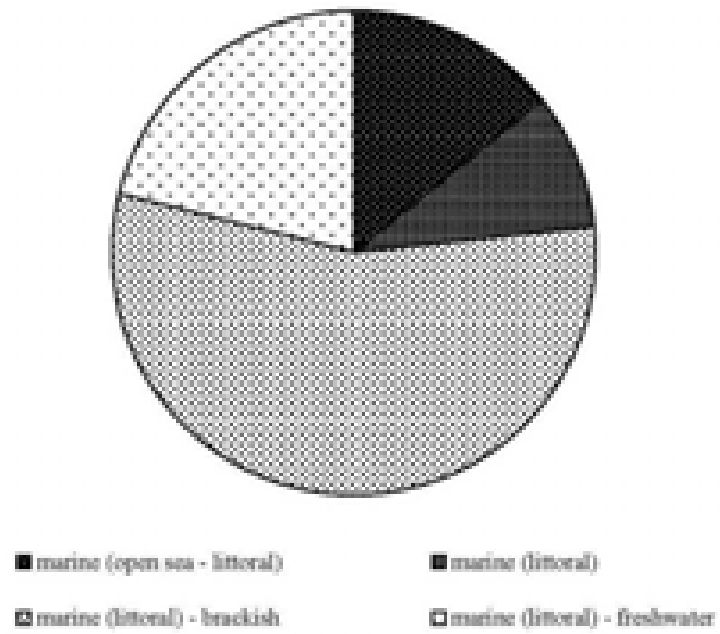

Figure 10.3 Habitats of fishes identified at Man Bac 2004-2005 (\%MNI).

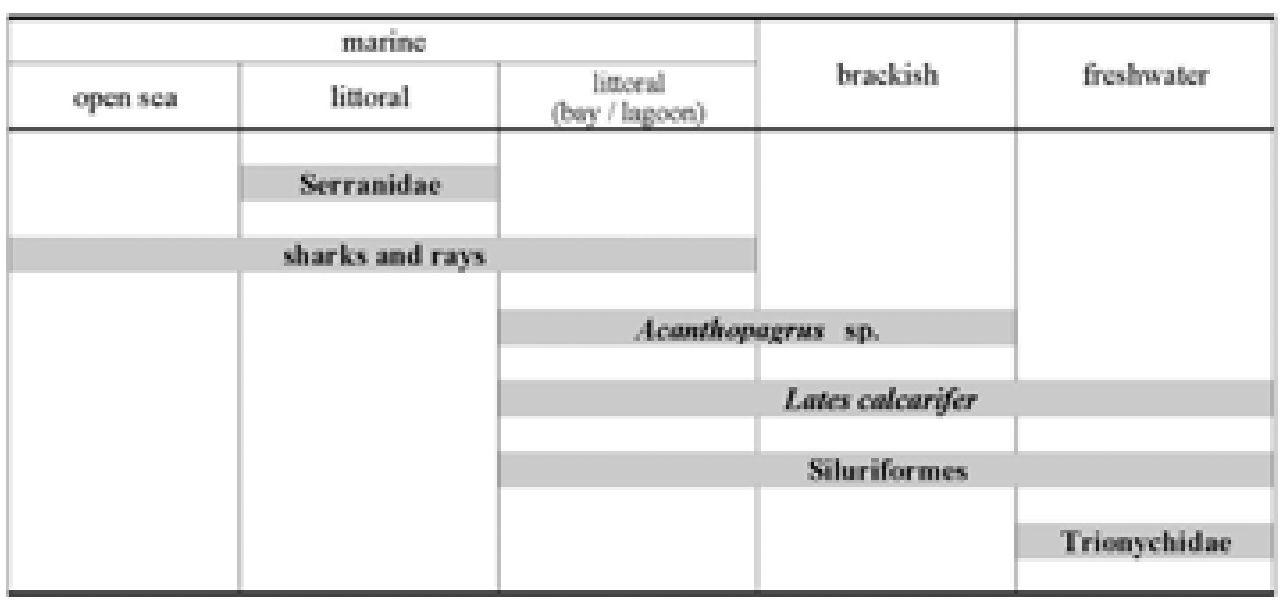

Figure 10.4 Habitats of the dominant fishes at Man Bac (Trionychidae are also shown). 
and line) since they inhabit relatively deep waters (see Clark and Szabó 2009; Ono and Clark 2010). Although no fishing hooks have been found at the site, considering Siluriformes, Lates calcarifer and Serranidae are all carnivores with a large mouth and that large individuals were caught, it is possible that some of the bone pointed tools, which are relatively short and pointed at both ends, were used as "gorges".

It needs to be noted that in the sieved samples, bones of smaller fishes, including types of fishes not present in the in situ recovered assemblage such as Clupeidae and Cyprinidae, were identified. Therefore, it is likely that these smaller fishes were also caught to a certain extent. If further research is done on these smaller fish remains, the observations described above may have to be revised.

Among the specimens of large Serranidae, a maxillary and several vertebrae with cutting traces by a large axe-like blade were found (Table 10.7, Figure 10.1, Nos. 9 and 11). Many stone axes were excavated at the site (Dung 2006), and were possibly used for butchering these large fishes.

Table 10.6 Estimated fishing grounds and technologies used for the dominant fish taxa caught at Man Bac.

\begin{tabular}{|c|c|c|}
\hline taxon & fishing ground & technology \\
\hline sharks & marine (details unknown) & unknown (hook and line / spears ?) \\
\hline rays & marine (details unknown) & unknown \\
\hline Siluriformes & marine (bay / lagoon) - freshwater & hook and line / spears \\
\hline Lates calcarifer & marine (bay / lagoon) - freshwater & hook and line / spears \\
\hline Serranidae & marine (littoral) & hook and line / (spears?) \\
\hline Acanthopagrus sp. & marine (bay / lagoon) - estuaries & spears / (hook and line?) \\
\hline
\end{tabular}

Table 10.7 Modified fish remains from Man Bac.

\begin{tabular}{llccll}
\hline taxon & common name & layer & sample bag & element & modification \\
\hline Rajiformes A & Rays (type A) & I & 98 & vertebra & perforated ? \\
& & I & 146 & vertebra & perforated \\
& & I & 101 & vertebra & perforated \\
& & II & 237 & vertebra & perforated \\
& & II & 219 & vertebra & perforated \\
& & II & 217 & vertebra & perforated \\
Lates calcarifer & barramundi & II & 215 & vertebra & perforated \\
Serranidae (large) & Groupers (large) & I & 158 & maxillary & perforated ? \\
Serranidae (large) $?$ & Groupers (large) ? & I & 151 & caudal vertebra & cut marks \\
& & I & 75 & caudal vertebra & artificially cut ? \\
& & II & 182 & caudal vertebra & artificially cut ? \\
Acanthopagrus sp. & Black Seabream & II & 180 & caudal vertebra & artificially cut ? \\
& & 329 & anal spine & polished at the tip \\
\hline
\end{tabular}

\section{SUMMARY}

The dominant fishes caught by the Man Bac community include Acanthopagrus sp., sharks and rays, Lates calcarifer, Siluriformes and Serranidae. The large size of Siluriformes, Lates calcarifer and Serranidae is a unique characteristic and it is 


\section{T. TOIZUMI ET AL.}

likely that they were caught with spears, or hooks and lines. It is likely that the main fishing grounds ranged from marine embayments or lagoons to brackish waters such as estuaries, with freshwater fishing activities being relatively limited.

\section{ACKNOWLEDGEMENTS}

We would first like to express our deep thanks to the following people for their help with analysing the material: Dr. Nguyen Kim Dung, Dr. Nguyen Lan Cuong, and Mr. Manabu Uetsuki.

\section{LITERATURE CITED}

Dung NK. 2006. Preliminary report on the Vietnamese - Japanese - Australian archaeological excavation at Man Bac site. In: Matsumura editor. Anthropological and Archaeological Study on the Origin of Neolithic People in Mainland Southeast Asia. Report of Grant-in-Aid for International Scientific Research (unpublished). p 88-128.

Clark G, Szabó K. 2009. The fish bone remains. In The Early Prehistory of Fiji, Clark GR, Anderson AJ (eds). ANU E Press: Canberra; 213-230. Terra Australis 31.

Masuda H, Araga C, Yoshino T. 1980. Coastal Fishes of Southern Japan. Tokyo: Tokai Daigaku Shuppankai.

Masuda H, Kobayashi Y. 1994. Grand Atlas of Fish Life Modes. Tokyo: Tokai Daigaku Shuppankai.

Ono, R. and Clark, G. 2010. A 2500-year record of marine resource use on Ulong Island, Republic of Palau. International Journal of Osteoarchaeology DOI: 10.1002/oa.1226.

Toizumi T. 1988. A method of seasonality estimation based on seasonal cycle of refuse deposition observed in the shell middens. Bull Natn Mus Japan Hist 29: 197-233. (in Japanese with English summary)

Toizumi T. 2000. Prehistoric fishery in the Final Jomon period around Atumi peninsula, central Japan. Zoo-archaeol 14: 23-38. (in Japanese) 